\title{
Hospice and Palliative Care Services in South Korea Supported by the National Health Insurance (NHI) Program
}

\author{
Yong Joo Rhee1,2 \\ ${ }^{1}$ Department of Health Sciences, Dongduk Women's University, Seoul, South Korea \\ ${ }^{2}$ Department of Psychiatry and Behavioral Sciences, Feinberg School of Medicine, Northwestern University, \\ Chicago, USA \\ Email: yrh759@dongduk.ac.kr, yongjoo.rhee@gmail.com
}

Received 12 May 2015; accepted 9 June 2015; published 12 June 2015

Copyright (C) 2015 by author and Scientific Research Publishing Inc.

This work is licensed under the Creative Commons Attribution International License (CC BY). http://creativecommons.org/licenses/by/4.0/

(c) (i) Open Access

\section{Abstract}

Previous main body of research on end-life-care in South Korea has focused on developing services quality in hospital settings or service payment system in National Health Insurance Program. The delivery system of hospice and palliative care services has evolved in diverse ways but there is little research on reviewing the past history of development and whole picture of them so far. So, the aim of this study is to review the old hospice and palliative care system and also to introduce the current one supported by the National Health Insurance Program in South Korea. The palliative care or hospice services in South Korea have been available in diverse settings and provided by different organizations (i.e. catholic hospitals or charity organizations). Finally, it was set up in 2004 that the hospice team or official Palliative Care Units (PCUs) was established in hospitals, in order to meet the end-of-life care for the patients with terminal cancer under the Cancer Control Act. The current hospice and palliative care services such as pain management, bereavement services, and counselling can be reimbursed by National Health Insurance program since 2008 . Nevertheless hospice and palliative care services are available to dying patients, yet the utilization rate of hospice and palliative care services or the length of stay in the palliative care unit (PCU) is still relatively short compared to other country systems. South Korea is undergoing several efforts to expand the services in PCU along with the development of quality indicators for PCU. Hospice and palliative care services are still new in the health care system and unfamiliar to the public so it requires raising awareness for medical professionals and the public as well as further research.

\section{Keywords}

Hospice, Palliative Care, South Korea, National Health Insurance Program (NHI) 


\section{Introduction}

Hospice or palliative care is a relatively new concept in South Korea under its national health care system. Even though hospice care has been available through religious organizations such as the Gabari Catholic Organization since 1963, the services were not considered "professional” or "medical” by the public. In 1980, a Catholic general hospital set up a hospice unit as part of an oncology unit [1]-[3]. Previously, Catholic nuns or nurses who worked with patients with terminal illnesses provided comfort care in the hospital or in patients' homes. Therefore, hospice care was just considered a service that voluntary organizations performed.

Since 2008, hospice and palliative care has been offered to patients with terminal cancer in certified hospitals with the support of the National Health Insurance Program [4]. However, initial hospice and palliative care services started as under the Cancer Control Policy in 2004. At this time, South Korea developed a long-term health policy to deal with major cancers which were and still are the leading cause of deaths among South Koreans. After implementing the First 10-year Plan for National Cancer Control (1996 to 2005), the South Korean government launched the Second 10-year Plan for National Cancer Control (2006 to 2015) at the national level. The new plan included substantial data and new efforts to reduce the prevalence of cancer breakouts and to improve care for patients with cancer. With the Revised Second 10-year Plan for National Cancer Control (2011 to 2015), hospice and palliative care services were recognized as official services under the Cancer Control Act of 2004 after conducting a pilot project for hospice and palliative care services between 2003 and 2004. Also, the Ministry of Health and Welfare enacted the Notification of Palliative Care Institution Designation Standards in 2008 (i.e. manpower, devices, education) and monitored the quality of hospice and palliative care in participating institutions and collected data to justify the cost. After two additional pilot projects, the National Health Insurance program developed a reimbursement system for hospice and palliative care services, detailed requirements for providers, and quality indicators for services [1] [5]-[8].

This study will introduce the background of the development of hospice and palliative care services in South Korea, explain current services and their utilization, and identify new efforts for better hospice and palliative care in South Korea. Furthermore, this study will address the future direction of hospice and palliative care services to meet the needs of South Koreans.

\section{Background of the Development of Hospice and Palliative Care Services in South Korea}

\subsection{Target and Services of Hospice and Palliative Care in South Korea}

"Hospice and palliative care” in South Korea can be explained as end-of-life care for dying patients. It is available mainly in hospital setting. Independent hospice clinics and free-stranding hospice organizations do not exist in South Korea. According to the definition of palliative care services supported by the Cancer Control Act Article 2, a "Terminal Cancer Patient" is defined as a patient who does not have the potential to recover and is expected to die within a few months due to aggressive declines brought on by his or her symptoms. "Hospice and Palliative Care Service” is defined as a comprehensive care service that aims increase the quality of life among terminal cancer patients, assist their families in assessing physical, psychosocial, and spiritual domains, and evaluate treatment options for pain management and symptom relief [9].

To accomplish these aims, Palliative Care Units (PCUs) in hospitals provide following major categories of services such as pain and symptom relief management, bereavement management, support services, spiritual care services and therapeutic programs. With pain and symptom relief management, medical professionals (physicians and nurses) assess the pain and symptoms of patients (i.e. loss of appetite, cachexia, pain, breathing irregularities, skin appearance, and mental symptoms) during the initial visits and then manage them according to a care plan agreed upon during a team conference. Next is bereavement management is a service offered to patients and their families prior to a patient's death. The services provide assistance to patients and their families undergoing physiological changes prior to death. After death, providers of this service keep the family informed of the details remaining in the process. Support services for families that to help with bereavement processes are available for one year following after a patient's death that may have in regarding to death. Additionally, spiritual care services of unresolved personal issues are designed to offer support for patients in finding answers to spiritual questions such as a the meaning of life, closure and religious worship services. Therapeutic programs (i.e. horticulture, art, music, aroma therapy and massage) are also available to increase the quality of life and 
emotional stability of patients. Patients and their families can also agree to receive pain control and physical symptom management, social and economic care, emotional care, safety enhancement care, nurse visits, and terminal care at home through home hospice if facing patient with terminal cancer. A 24-hour-hotline counselling and visitation services is available for emergencies during night and weekends.

\subsection{Official Government Involvement}

The Ministry of Health and Welfare in South Korea has been involved in developing hospice and palliative care services heavily. They have been responsible for monitoring the licensing of professionals, regulating requirements, and building up a database for clinical and policy purpose. The Ministry of Health and Welfare along with the National Cancer Center have played major roles. The National Cancer Center is a national organization tasked with performing basic and clinical cancer research on cancer, providing medical care services for cancer patients, offering education and training, and assisting the government in formulating regulations. Both the Ministry of Health and Welfare and the National Cancer Center have played major roles in the research and implementation of end-of-life care in South Korea.

A pilot project to assess the costs involved in hospice and palliative care services was launched in 2008. After the initial pilot project (2008-2011), a second pilot project was begun in 2012 and remains ongoing. Twelve institutes were engaged with these pilot projects to assist in establishing a payment system for hospice and palliative care.

\subsection{Quality Control for Hospice and Palliative Care Services}

A number of studies were conducted on quality issues related to hospice and palliative care services even before South Korean government officially incorporated these services into the National Health Insurance Program. These studies addressed in part the education of medical providers, the outcomes of hospice and palliative care, and approaches to pain management [3] [10] [11].

Due to a lack of comparable data, South Korea established a national database for patients who receive hospice and palliative care in hospitals throughout the nation.

\subsubsection{Terminal Cancer Patient Database (DB) Registry}

The National Cancer Center estimates and provides basic statistics among terminal cancer patients who received hospice and palliative care services. This data is then utilized for health care policy decisions to support patients with terminal cancer. This Terminal Cancer Patient DB Registry includes all information about palliative care, home visits, hospitalization and discharge, and bereavement information. Furthermore, this database also includes the results of patient and family surveys in regarding to their satisfaction with the services provided.

\subsubsection{Education of Medical Professionals Providing Services in the PCUs}

The National Cancer Center functions plays a major role in educating professionals who works in PCUs and distributing information on how to manage PCUs through workshops and training for hospice and palliative care services. People who receive special training from the National Cancer Center become experts who then visit PCUs in hospitals and provide mentoring for medical professionals working there. They train other in the protocol for dealing with difficulties in the PCU and for promoting the quality of care in the PCU. Experts can also provide these services to hospitals that want to set up a PCU that plan to offer a PCU in the near future. The usual spectrum of training involves: management and evaluation, patient and family education and counseling, relief therapy, spiritual care, bereavement care, and home hospice. In addition, the South Korean government established requirements and regulations for hospice and palliative care in hospitals in areas such as facilities, personnel, and equipment.

\subsection{Settings for Hospice and Palliative Care Services in South Korea}

To expand the services of palliative care for terminal cancer patients, the Ministry of Health and Welfare enacted the Notification of Palliative Care Institution Designation Standards in September 2008, and by 2014, 54 palliative care institutions were established. Since 2005, the Ministry of Health and Welfare has subsidized public palliative care institutions to be subsidized for their operating expenses [4]. 


\subsubsection{Palliative Care Units (PCUs) in Hospitals}

This is the most common format for providing hospice and palliative care services for terminal cancer patients. Services such as pain management and bereavement care are provided in independent PCUs in general hospitals to help patients and their families [1] [12].

\subsubsection{Home Care for Terminal Cancer Patients}

In 1990, Medical Act 56 was passed to allow registered nurses to visit homes in order to provide home care for patients [5]. This type of end-of-life care was not set up as an official "home hospice", but most of the services provided are identical to those provided to terminal cancer patients at home such as pain and symptoms management (i.e. medication). It stands as a subset service of palliative care that hospital provides. If a patient cannot be hospitalized for some reason and registered nurses are available, home care can and does occur but the visit is not considered as an independent service under the National Health Insurance program.

\subsubsection{Home Visit Provided by the Community Health Center for Low Income Patients}

There were pilot projects conducted to provide home hospice for terminal cancer patients through community health centers between 2000 and 2002 [13] [14]. This home hospice service was provided by the various community health centers and offered diverse supports such as music therapy, physical therapy, counseling, and pain management. Some support systems were covered by social services because these patients were medical aid beneficiaries, and thus all their services were subsidized by the government. The overall outcomes and levels of satisfaction were high, but these services were limited to low income, medical aid patients [5].

\subsubsection{Reimbursements and Medical Costs for the PCU}

The current reimbursement for hospice and palliative care services is per diem, which uses a flat rate per day, mainly differentiated by a provider's size (i.e. tertiary hospital, hospital, or clinic) for institutes involved with the pilot project. A few supplementary services are paid according to a fee schedule that takes into consideration the resources (i.e. nurse level) and time needed to provide a service (Table 1). Since 2008, only institutes involved with hospice pilot projects have been reimbursed by the National Health Insurance program, and the reimbursement coverage has been extended for 2015 for all hospice and palliative care services. Most supplementary services, irrelevant to medical services such as meals, music or art therapy, are not included.

\section{Utilizations of Hospice and Palliative Care Services}

In 2012, 8472 cancer patients received services from 44 palliative care institutions. Among those who died from cancer only, $11.9 \%$ received palliative care from these institutions. In 2011, 87.7\% of cancer deaths occurred at health institutions, 9.3\% occurred in patients' homes and 1.3\% during transfer, respectively [4]. In 2013, 8084

Table 1. Providers of hospice and palliative care in South Korea in 2014.

\begin{tabular}{|c|c|c|c|}
\hline \multirow{3}{*}{ Provider Information } & \multicolumn{3}{|c|}{ Hospice and Palliative Care Services } \\
\hline & \multicolumn{2}{|c|}{ Organizations } & \multirow[b]{2}{*}{ Total Number } \\
\hline & $\begin{array}{l}\text { Involved with Pilot Project to } \\
\text { Develop Palliative Care Services }\end{array}$ & $\begin{array}{l}\text { Not involved with Pilot Project to } \\
\text { Develop Palliative Care Services }\end{array}$ & \\
\hline Number of Organizations & 12 & 42 & 54 \\
\hline Number of Beds & 206 & 662 & 868 \\
\hline Payment System & Per Diem & Fee for Service & \\
\hline $\begin{array}{l}\text { Out of Pocket Money } \\
\text { Payment }\end{array}$ & $5 \%$ & $5 \%$ & \\
\hline Provided System & Separate Units in Hospital & Separate Units (or Beds) in Hospital & \\
\hline Government Funding & Yes & Yes & 2,720,000,000 (Korean Won) \\
\hline
\end{tabular}

Source: National Cancer Center (2014), Support for activation of palliative care service. Seoul, Korea: National Cancer Center. 
cancer patients obtained services from palliative care institutions. According to the type of cancer, lung cancer patients received the most assistance was the highest (1329, 19.7\%), followed by gastric cancer (883, 13.1\%), colorectal cancer (684, 10.1\%), pancreatic cancer (619, 9.2\%), and liver cancer (584, 8.7\%) [4].

In general, dying patients who received hospice and palliative care services did not utilize expensive care and treatment plans prior to death, therefore resulting in overall lower costs for health care services [15]. Medical expenditures for patients who received hospice and palliative care services prior to death was almost half that of patients who received conventional treatments services [16]. The average length of stay in hospice and palliative care was18 days among those who received end-of-life care [17].

\section{Discussions}

South Korea has done well to develop end-of-life care under the National Health Insurance program within the past 15 years, but new efforts are required. South Korean citizens are generally aware of the need for end-of-life care [18] [19] and are becoming more familiar with these services. However, these services continue to be difficult to access. Furthermore, the duration under which services are provided needs to be addressed for patients who receive hospice and palliative care before death. [17]. The South Korean government is dedicating more resources oncampaigns to raise awareness of these end-of-life care services through the media and workshops at community health centers [16] [20].

\subsection{Home Hospice}

Currently, only low-income patients with terminal cancer are able to access home hospice [2] [14]. In the past, reimbursement for home hospice care was not available; and therefore $79 \%$ of home hospice was provided free of charge through religious or other volunteer organizations [14]. Although the home is considered to be an ideal place for one's life to end, [21] [22], currently only about $10 \%$ of South Korean citizens die at home [23]. These findings indicate that the current support system is still lacking, especially when compared to the US or other countries in Europe. Further attention is needed [24] [25].

\subsection{Extensions and Quality Assurance of Hospice and Palliative Care Services}

The body of research on end of life care illustrates that the hospice use increased over time after a similar program from the US was instituted in South Korea [26] [27]. Medicare for dying patients in the US has expanded the recipients of hospice and it has allowed for enrollment of non-cancer patients [27]. For example, patients with dementia are becoming an increasing proportion of hospice enrollees in the US, and the quality of hospice care for this population has been studied [28]. South Korea is facing a similar trend with an increasing number of patients with dementia [4]. However, at this time, South Korea is only offering hospice and palliative care in hospitals for terminal cancer patients. The coverage supported by the National Health Insurance program should aim to include for patients with dementia or other terminal illness.

In addition to extending of end-of-life care, the National Health Insurance program, also take steps to guarantee the quality of care provided. Previous studies and current monitoring systems have focused on structural level aspects such as equipment and personnel qualifications and training [4] [7] [8] [11] [16] [29]. Further standardized quality of indicators and processes should be developed and implemented.

\section{Conclusion}

Despite many challenges to implementing services, South Korea, over the past decade, has developed and improved its end-of-life care for terminal cancer patients through its National Health Insurance program. Ongoing care and appropriate policy changes should be considered based on more in-depth research. More empirical research is needed on quality assurance for hospice and palliative care and the development of a comprehensive service delivery system for end-of-life care in hospital settings and in communities in the future. Thus, these research findings can help to establish feasible and reliable health policy implications.

\section{Acknowledgements}

Author thanks for assistance that Hee-ae Kim provided for this manuscript. 


\section{References}

[1] Kim, J.S. (2004) Present Status and Future of Hospice Palliative Care in Korea. Korean Journal of Medicine, 67, 327329.

[2] Kim, S.H., Chung, B.Y. and Xu, Y. (2009) Evaluation of a Home-Based Hospice and Palliative Care Program in a Community Health Center in Korea. Asian Nursing Research, 3, 24-30. http://dx.doi.org/10.1016/S1976-1317(09)60013-X

[3] Yun, Y., Choi, E.S., Lee, I.J., Rhee, Y.S., Lee, J.S., You, C.H., Kim, H.S. and Paek, Y.J. (2002) Survey on Quality of Hospice-Palliative Caere in Korea. Korean Journal of Hospice and Palliative Care, 5, 31-42.

[4] Center, N.C. (2015) Cancer Facts and Figures 2014 in the Republic of Korea. Seoul.

[5] Kim, B. (2011) Current and Future of Hospice and Palliative Care in South Korea. Korean Journal of Hospice and Palliative Care, 14, 191-196.

[6] Kim, J., Kim, S.M., Joo, J.S. and Lee, K.S. (2012) Factors Associated with Medical Cost among Patients with Terminal Cancer in Hospice Units. Journal of Palliative Care, 28, 5-12.

[7] Kim, S. (2006) Development of the Service Mode for Hospice Palliative Care in Terminal Cancer Care. National Cancer Control Planning Board, Seoul.

[8] Yun, Y., et al. (2002) Survey on the Quality of Hospice Palliative Care Programs in Korea. Korean Journal of Hospice and Palliative Care, 5, 31-42.

[9] Center, N.C. (2014) Support for Activation of Palliative Care Service. Seoul.

[10] Kang, J., Shin, D.W., Hwang, E.J., Kim, H., Ahn, H. and Yoo, Y.S. (2009) Hospice Education among Hospice Professionals and Its Regional Variations in Korea-Outcomes from a 2008 Hospice Palliative Care Institutions Support Project). Korean Journal of Hospice and Palliative Care, 12, 132-138.

[11] Yun, Y. (2003) Study for Korean Standardization of Hospice Palliative Care Service. National Cancer Control Planning Board, Seoul.

[12] Kyung, M.H., Jang, Y.M., Han, K.H. and Yun, Y.H. (2010) Current Status and Activation Plan of Hospice Palliative Care in Korea-Based on Hospice Palliative Care Facilities Survey. Korean Journal of Hospice and Palliative Care, 13, 143-152.

[13] Lee, Y.S. (2013) The Past, Present and Future Strategies of Korean Social Work in Hospice and Palliative Care. Korean Journal of Hospice and Palliative Care, 16, 65-73. http://dx.doi.org/10.14475/kjhpc.2013.16.2.065

[14] Park, C.-S., Yoon, S. and Jung, Y. (2013) The Status of Home-Based Hospice Care in Korea. Korean Journal of Hospice and Palliative Care, 16, 98-107. http://dx.doi.org/10.14475/kjhpc.2013.16.2.098

[15] Emanuel, E. (1996) Cost Saving at the End of Life: What Do the Data Show? Journal of the American Medical Association, 275, 1907-1914. http://dx.doi.org/10.1001/jama.1996.03530480049040

[16] Cho, Y., Choi, J.K., Tae, Y.H., Kim, J.Y. and Kim, J.D. (2015) Support for Activation of Hospice and Palliative Care Service. National Health Insurance Services, Seoul.

[17] Baek, Y.J., Shin, D.W., Choi, J.Y., Kang, J., Mo, H.N., Kim, Y.H., et al. (2011) Late Referral to Palliative Care Services in Korea. Journal of Pain and Symptom Management, 41, 692-699. http://dx.doi.org/10.1016/j.jpainsymman.2010.06.019

[18] Lee, J.K., Yun, Y.H., An, A.R., Heo, D.S., Park, B.-W., Cho, C.-H., et al. (2013) The Understanding of Terminal Cancer and Its Relationship with Attitudes toward End-of-Life Care Issues. Medical Decision Making, 34, 720-730. http://dx.doi.org/10.1177/0272989X13501883

[19] Lee, Y.E., Choi, E.J., Park, J.S. and Shin, S.H. (2013) Perception and Knowledge of Hospice Care and Attitude toward Death Held by Medical Professionals from the Same Region in Korea. Korean Journal of Hospice and Palliative Care, 16, 242-252. http://dx.doi.org/10.14475/kjhpc.2013.16.4.242

[20] Choi, J., Shin, D.W., Kang, J., Baek, Y., Mo, H.N., Nam, B., Seo, W.S., Park, J.H., Kim, J.H. and Jung, K.T. (2012) Variations in Process and Outcome in Inpatient Palliative Care Services in Korea. Supportive Care in Cancer, 20, 539547. http://dx.doi.org/10.1007/s00520-011-1115-y

[21] Ahlner-Elmqvist, M., Jordhøy, M., Jannert, M., Fayers, P. and Kaasa, S. (2004) Place of Death: Hospital-Based Advanced Home Care versus Conventional Care: A Prospective Study in Palliative Cancer Care. Palliative Medicine, 18, 585-593. http://dx.doi.org/10.1191/0269216304pm924oa

[22] Siden, H., Miller, M., Straatman, L., Omesi, L., Tucker, T. and Collins, J. (2008) A Report on Location of Death in Paediatric Palliative Care between Home, Hospice and Hospital. Palliative Medicine, 22, 831-834. http://dx.doi.org/10.1177/0269216308096527

[23] Yun, Y.H., Lim, M.K., Choi, K.-S. and Rhee, Y.S. (2006) Predictors Associated with the Place of Death in a Country 
with Increasing Hospital Deaths. Palliative Medicine, 20, 455-461. http://dx.doi.org/10.1191/0269216306pm1129oa

[24] Reyniers, T., Deliens, L., Pasman, H.R., Morin, L., Addington-Hall, J., Frova, L., et al. (2015) International Variation in Place of Death of Older People Who Died from Dementia in 14 European and Non-European Countries. Journal of the American Medical Directors Association, 16, 165-171. http://dx.doi.org/10.1016/j.jamda.2014.11.003

[25] Moens, K., et al. (2015) Where Do People Living with Parkinson's Disease Die? A Population-Level Study in 11 Countries. BMC Palliative Medicine, in Press.

[26] Han, B., Remsburg, R.E., McAuley, W.J., Keay, T.J. and Travis, S.S. (2006) National Trends in Adult Hospice Use: 1991-1992 to 1999-2000. Health Affairs, 25, 792-799. http://dx.doi.org/10.1377/hlthaff.25.3.792

[27] Dy, S., Wolff, J.L. and Frick, K.D. (2007) Patient Characteristics and End-of-Life Health Care Utilization among Medicare Beneficiaries in 1989 and 1999. Medical Care, 45, 926-930. http://dx.doi.org/10.1097/MLR.0b013e31812714a5

[28] Albrecht, J., Gruber-Baldini, A.L., Fromme, E.K., McGregor, J.C., Lee, D.S. and Furuno, J.P. (2013) Quality of Hospice Care for Individuals with Dementia. Journal of the American Geriatrics Society, 61, 1060-1065. http://dx.doi.org/10.1111/jgs.12316

[29] Chung, B., Xu, Y. and Kwak, C. (2005) Hospice and Hospice Care in Korea: Evolution, Current Status, and Challenges. Home Health Care Management \& Practice, 18, 73-77. 